\title{
Aplicação do 1-metilciclopropeno e sua influência no processo de remoção da adstringência com etanol em caqui ‘Giombo' refrigerado
}

\author{
Application of 1-methylcyclopropene and its influence in the process of astringency removal of \\ 'Giombo' persimmon by using ethanol \\ Felipe de Angelis Monteiro Terra ${ }^{\mathrm{I}}$ Fernando Kazuhiro Edagi ${ }^{\mathrm{I}}$ Fabiana Fumi Cerqueira Sasaki ${ }^{\mathrm{I}}$

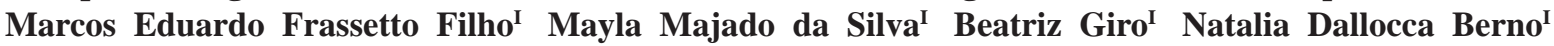 \\ Ricardo Alfredo Kluge ${ }^{\mathrm{I}^{*}}$
}

\section{RESUMO}

Este trabalho tem como objetivo verificar a possibilidade de aplicação de vapor de etanol para a destanização, associado ao 1-metilciclopropeno (1-MCP) para prolongar o armazenamento de caquis 'Giombo' em ambiente refrigerado, evitando rápido amolecimento de polpa, decorrente do processo de destanização. Os seguintes tratamentos foram realizados: T1) controle: frutos sem tratamento, apenas colocados sob armazenamento refrigerado (AR); T2) aplicação de etanol (3,50mL kg-1 durante 12h) + AR; T3) aplicação de 1-MCP (1000nL $L^{-1}$ durante 12h) + AR; T4) aplicação de 1-MCP e posterior aplicação de etanol + AR; T5) aplicação de 1-MCP + AR + aplicação de etanol após o AR. O AR consistiu no armazenamento dos frutos por 30 dias $a 5^{\circ} \mathrm{C}$ e $90 \%$ UR. Posteriormente, os frutos foram mantidos a $25^{\circ} \mathrm{C}$ durante 15 dias. Frutos não tratados (controle) e os tratados com 1-MCP apresentaram maior firmeza de polpa que os demais tratamentos, mas não alcançaram a destanização. Frutos submetidos ao etanol apresentaram rápida perda de adstringência, acompanhado de elevada perda de firmeza. O 1-MCP, quando aplicado antes do armazenamento, em frutos que posteriormente à refrigeração foram tratados com etanol, manteve mais alta a firmeza de polpa em relação aos frutos que foram submetidos ao etanol imediatamente à aplicação do 1-MCP e aqueles tratados apenas com etanol. Esse tratamento pode ser utilizado nessa cultivar para manter a qualidade durante a comercialização.

Palavras-chave: Diospyros kaki, etileno, tanino, etanol, firmeza de polpa.

\section{ABSTRACT}

This study is carried out with the objective to verify the ethanol vapor application possibility for astringency removal, associated with 1-methylcylopropene (1-MCP) to increase 'Giombo' persimmons shelf life under cold storage, avoiding quick flesh softening by astringency removal process. The following treatments were performed: T1) control: fruit without treatment, only cold stored (CS); T2) application of ethanol $\left(3.50 \mathrm{~mL} \mathrm{~kg}^{-1}\right.$ for 12 hours) + CS; T3) application of 1-MCP (1000nL L-1 for 12 hours) + CS; T4) application of 1-MCP and later application of ethanol + CS; T5) application of 1-MCP + CS + application of ethanol after cold storage. Fruit were cold stored (CS) for 30 days at $5^{\circ} \mathrm{C}$ and $90 \% \mathrm{RH}$. After CS, fruit were exposure to $25^{\circ} \mathrm{C}$ during 15 days. The untreated fruits (control) and the ones treated with 1-MCP showed higher flesh firmness than the rest of the treatments, but did not reach detannization. Fruit treated with ethanol showed fast loss of astringency and firmness. The 1-MCP, when applied before CS, to fruits which after CS were treated to ethanol, kept higher flesh firmness as compared to the fruits which were treated with ethanol immediately after the application of 1-MCP and those treated only with ethanol. This treatment might be used in Giombo persimmon in order to maintain the fruit quality during marketing.

Key words: Diospyros kaki, ethylene, tannin, ethanol, flesh firmness.

\section{INTRODUÇÃO}

O Estado de São Paulo é o maior produtor nacional de caqui, com $60 \%$ da produção do Brasil. Desse total, 50\% são da cultivar 'Rama Forte', 19\% de 'Giombo', 15\% de 'Fuyu', 14\% de 'Taubaté' e 2\% de outras (CAMARGO FILHO et al., 2003). O caqui ‘Giombo' é pertencente ao grupo variável, o qual apresenta polpa clara e adstringente, quando ocorre o desenvolvimento partenocárpico dos frutos, e polpa escura e não adstringente na presença de sementes (CAMPO-DALL'ORTO et al., 1996). Ele vem sendo extensivamente cultivado, devido à excelente qualidade sensorial de seus frutos. Considerando que a maioria dos frutos colhidos de caqui 'Giombo' encontra-se adstringente no momento da colheita, há

IDepartamento de Ciências Biológicas, Escola Superior de Agricultura “Luiz de Queiroz” (ESALQ), Universidade de São Paulo (USP), Av. Pádua Dias, 11, CP 9, 13418-900, Piracicaba, SP, Brasil. E-mail: rakluge@usp.br. *Autor para correspondência. 
a necessidade de se realizar o processo de remoção de adstringência, visando à obtenção de frutos não adstringentes por ocasião da comercialização (EDAGI \& KLUGE, 2009).

Os métodos tradicionalmente utilizados para a remoção da adstringência são baseados no acúmulo de acetaldeído na polpa, o qual induz a polimerização das moléculas solúveis de taninos, tornando-as insolúveis e não adstringentes. Os principais métodos utilizados são as aplicações de etanol ou etileno e a exposição dos frutos a altas concentrações de dióxido de carbono (OSHIDA et al., 1996; ANTONIOLLI et al., 2001; EDAGI et al., 2009). Invariavelmente, esses processos de remoção da adstringência com aplicação de etanol ou etileno, embora eficientes, resultam em perda excessiva da firmeza de polpa, o que não é desejável para essa cultivar (ANTONIOLLI et al., 2000; 2001; 2002).

A redução da firmeza da polpa é um processo associado ao amadurecimento, sendo que, quanto mais rápida a perda de firmeza menor é a vida útil do fruto. A maioria dos processos relacionados ao amadurecimento dos frutos climatéricos, como o caqui, é dependente da produção e ação do etileno. Diferentes métodos pós-colheita têm sido aplicados visando a retardar o processo do amadurecimento, sendo eles a refrigeração, a modificação da atmosfera e a aplicação de biorreguladores. Essas técnicas buscam atenuar os efeitos do etileno, retardando o amadurecimento (CHITARRA \& CHITARRA, 2005).

O 1-metilciclopropeno (1-MCP) é uma molécula bloqueadora do sítio de ação do etileno (SISLER \& SEREK, 1997; BLANKENSHIP \& DOLE, 2003). Em nível celular, essa molécula se liga aos receptores de etileno, bloqueando a sua ação. Portanto, a aplicação de 1-MCP retarda o aparecimento dos sintomas de senescência relacionados ao etileno, aumentando o tempo de armazenamento dos frutos e mantendo a qualidade desejada pelo consumidor (PEREIRA \& BELTRAN, 2003; WATKINS, 2006). ORTIZ et al. (2005) observaram que a aplicação de 1-MCP em caquis 'Rendaiji', submetidos ao tratamento de remoção de adstringência retardou o início do amolecimento de polpa dos frutos em até 11 dias após a colheita. Estes autores relataram também que, 19 dias após a colheita, 25\% dos frutos tratados com 1-MCP haviam amolecido, enquanto que, nos frutos não tratados, essa porcentagem era de $80 \%$.

O 1-MCP também pode ter outros efeitos quando aplicado em caquis submetidos ao armazenamento refrigerado em temperaturas próximas a $0^{\circ} \mathrm{C}$. Normalmente, próximo a essa temperatura, o caqui apresenta amolecimento, devido às injúrias provocadas pelo frio (ARNAL \& DEL RÍO, 2004; SALVADOR et al., 2005) o que, consequentemente, reduz o período de armazenamento pós-colheita. A suscetibilidade às injúrias pelo frio varia em função da cultivar, estádio de maturação e local de produção dos frutos (MARTINS \& PEREIRA, 1989). Para a cultivar 'Fuyu' e cultivares semelhantes (não adstringentes), temperaturas entre $5^{\circ} \mathrm{C}$ e $15^{\circ} \mathrm{C}$ são mais propícias para manifestação das injúrias pelo frio (CRISOSTO et al., 2011). Por outro lado, PIO et al. (2003) recomendam utilizar temperaturas em torno de $5{ }^{\circ} \mathrm{C}$ para conservação de caquis. BLUM et al. (2008) também armazenaram caquis 'Giombo' a $4 \pm 1^{\circ} \mathrm{C}$ por, aproximadamente, 40 dias sem injúrias pelo frio. Comercialmente, nas regiões produtoras de caqui do Estado de São Paulo, caquis ‘Giombo’ são armazenados satisfatoriamente por longos períodos a $5^{\circ} \mathrm{C}$. PERÉZMUNUERA et al. (2005) observaram que a utilização de 1-MCP reduziu as injúrias pelo frio em caquis 'Rojo Brillante' armazenados por 40 dias a $1^{\circ} \mathrm{C}$. Este trabalho teve como objetivo verificar a possibilidade de aplicação de vapor de etanol para a destanização, associado ao 1-MCP e ao armazenamento refrigerado em caquis 'Giombo', visando obter frutos destanizados e com firmeza preservada, mantendo sua qualidade e, assim, prolongando o período de comercialização e oferta do produto.

\section{MATERIAL E MÉTODOS}

Caquis 'Giombo' colhidos na região

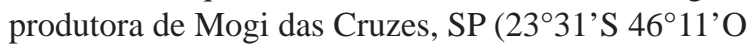
e $742 \mathrm{~m}$ de altitude), foram submetidos a seleção, obtendo-se um lote homogêneo quanto ao tamanho, formato, cor de casca e ausência de danos mecânicos. Na colheita, os frutos apresentavam firmeza em torno de $30 \mathrm{~N}$ e teor de tanino de $0,7 \mathrm{~g}$ de ácido gálico $100 \mathrm{~g}^{-1}$.

Os seguintes tratamentos foram realizados: T1) controle: frutos sem tratamento, apenas colocados sob armazenamento refrigerado (AR); T2) aplicação de etanol 3,50mL $\mathrm{kg}^{-1}$ durante $12 \mathrm{~h}+\mathrm{AR}$; T3) aplicação de 1-MCP 1000nL L-1 durante $12 \mathrm{~h}+$ AR; T4) aplicação de 1-MCP 1000nL L ${ }^{-1}$ durante $12 \mathrm{~h}$ e posterior aplicação de etanol 3,50 $\mathrm{mL} \mathrm{kg}^{-1}$ durante $12 \mathrm{~h}$ + AR; T5) aplicação de 1-MCP 1000nL L-1 durante $12 \mathrm{~h}+\mathrm{AR}+$ aplicação de etanol 3,50 $\mathrm{mL} \mathrm{kg}^{-1}$ durante 12h após o armazenamento refrigerado.

O volume de etanol (PA, marca Synth) estabelecido para os tratamentos foi colocado dentro de bandejas de alumínio e, em seguida, disposto na parte inferior de caixas plásticas herméticas (180L), sendo que cada caixa plástica continha aproximadamente 45kg de frutos. Em seguida, essas caixas foram 
fechadas hermeticamente para permitir a evaporação do etanol. Para a aplicação de 1-MCP (SmartFresh ${ }^{\mathrm{TM}}$ ), os frutos foram colocados nas mesmas caixas herméticas, contendo solução com a concentração desejada de 1-MCP. A manutenção das caixas a $22^{\circ} \mathrm{C} \pm 1^{\circ} \mathrm{C}$ e $90 \pm 5 \%$ UR proporcionou a vaporização do etanol e da solução de 1-MCP. A umidade relativa dentro das caixas foi mantida pelo acréscimo de água destilada na parte inferior de estrados, sobre os quais as caixas com os frutos foram colocadas.

O AR consistiu na manutenção dos frutos a $5^{\circ} \mathrm{C} \pm 1^{\circ} \mathrm{C}$ e $90 \pm 5 \%$ UR durante 30 dias. A temperatura de $5^{\circ} \mathrm{C}$ foi escolhida por ser a mais utilizada pelos produtores e economicamente viável. As avaliações foram realizadas antes do tratamento (caracterização do fruto, ou dia zero); um dia após a saída dos frutos do armazenamento refrigerado e a cada dois dias, durante 15 dias, quando os frutos ficaram expostos a $25^{\circ} \mathrm{C} \pm 1^{\circ} \mathrm{C}$ e $60 \% \pm 5 \%$ UR.

Os atributos de qualidade avaliados foram: a) Firmeza de polpa: medida com penetrômetro digital, marca Sammar, modelo 85261.0472TR, com ponteira de $8 \mathrm{~mm}$, efetuando-se duas leituras em lados opostos na região equatorial dos frutos, após a remoção de uma pequena porção da casca. Os resultados foram expressos em Newton (N); b) Índice de adstringência: foi realizado corte transversal na região equatorial do fruto, sendo a metade contendo o cálice, colocada em contato como papel de filtro banhado com uma solução de cloreto férrico (CAMPO-DALL'ORTO et al., 1996). O tanino, na forma solúvel, reage com o cloreto férrico, tornando-se escurecido. A avaliação foi feita por escala visual, através de notas atribuídas a cada fruto carimbado: 1 = não taninoso; 2 = ligeiramente taninoso; 3 = mediamente taninoso; 4 = taninoso; e 5 = muito taninoso; c) Teor de taninos solúveis: foi determinado espectrofotometricamente, segundo CARVALHO et al. (1990), com adaptações, segundo metodolgia de AGOSTINI-COSTA et al. (1999), pelo uso de Folin-Ciocauteau. Os resultados foram expressos em gramas de ácido gálico por 100 gramas de polpa (g 100g-1).

$\mathrm{O}$ delineamento experimental foi inteiramente ao acaso, em fatorial 5x8 (5 tratamentos e 8 períodos de armazenamento). Foram utilizadas quatro repetições por tratamento, constituídas de seis frutos. Os resultados obtidos foram submetidos à análise de variância e as médias foram comparadas pelo teste de Tukey a 5\% de probabilidade.

\section{RESULTADOS E DISCUSSÃO}

Durante o período de armazenamento em temperatura ambiente (15 dias), os frutos foram progressivamente perdendo a firmeza. Frutos tratados com etanol, isoladamente ou associado ao 1-MCP, foram os que apresentaram maiores perdas de firmeza, sendo que, no terceiro dia a firmeza encontravase abaixo de $15 \mathrm{~N}$, significativamente menor que a observada para os demais (Figura 1A). Os frutos tratados apenas com etanol foram descartados após 13 dias de armazenamento a $25^{\circ} \mathrm{C}$, devido ao excessivo amolecimento e à presença de podridões.

A aplicação de 1-MCP, antes da destanização com etanol, não evitou a perda de firmeza, que, no primeiro dia, à temperatura ambiente, caiu para valores próximos a $10 \mathrm{~N}$, estabilizando-se em seguida. CRISOSTO et al. (2011) recomendam valores mínimos de 22,2N para caquis 'Fuyu’ serem considerados firmes. Valores entre 10 e $15 \mathrm{~N}$ para o caqui 'Giombo' representam frutos excessivamente amolecidos, havendo dificuldades no manuseio (NORMAS DE CLASSIFICAÇÃO DO CAQUI, 2000). O 1-MCP aplicado isoladamente manteve da firmeza dos frutos em valores acima de $22 \mathrm{~N}$ durante 11 dias a $25^{\circ} \mathrm{C}$, mas impediu a destanização. Quando o etanol foi aplicado, após a retirada da refrigeração, em frutos previamente tratados com 1-MCP, também houve manutenção da firmeza durante a exposição à temperatura ambiente até o $11^{\circ}$ dia. Isso indica que a associação do 1-MCP com etanol, embora tenha reduzido aproximadamente $21,5 \%$ da firmeza inicial, pode ser feita com o objeitvo de manter a firmeza do fruto na comercialização, mas somente quando o etanol foi aplicado após a refrigeração de frutos previamente tratados com 1-MCP.

O processo de destanização, seja ele realizado com a utilização de etileno ou com vapores de etanol, geralmente acelera o amadurecimento, fazendo com que o fruto tenha sua firmeza reduzida muito rapidamente. Segundo ANTONIOLLI et al. (2002) e SALVADOR et al. (2007), uma das principais preocupações com relação ao armazenamento refrigerado de caqui é a acelerada perda da firmeza de polpa após a retirada da refrigeração. Alguns autores comprovaram que o amolecimento do fruto é dependente do etileno, que participa da ativação de enzimas degradativas da parede celular (NAKANO et al., 2002, 2003; HARIMA et al., 2003), uma vez bloqueada a sua ação com o 1-MCP, ocorre retenção na perda de firmeza.

Maior manutenção de firmeza também foi observada em caquis 'Fuyu' tratados com 1-MCP e armazenados a $0^{\circ} \mathrm{C}$, durante 90 dias (GIRARDI et al., 2003), e também por LUO (2007) em caquis 'Qiandaowuhe', tratados com 1-MCP e mantidos por 24 horas a $20^{\circ} \mathrm{C}$. ORTIZ et al. (2005) também 


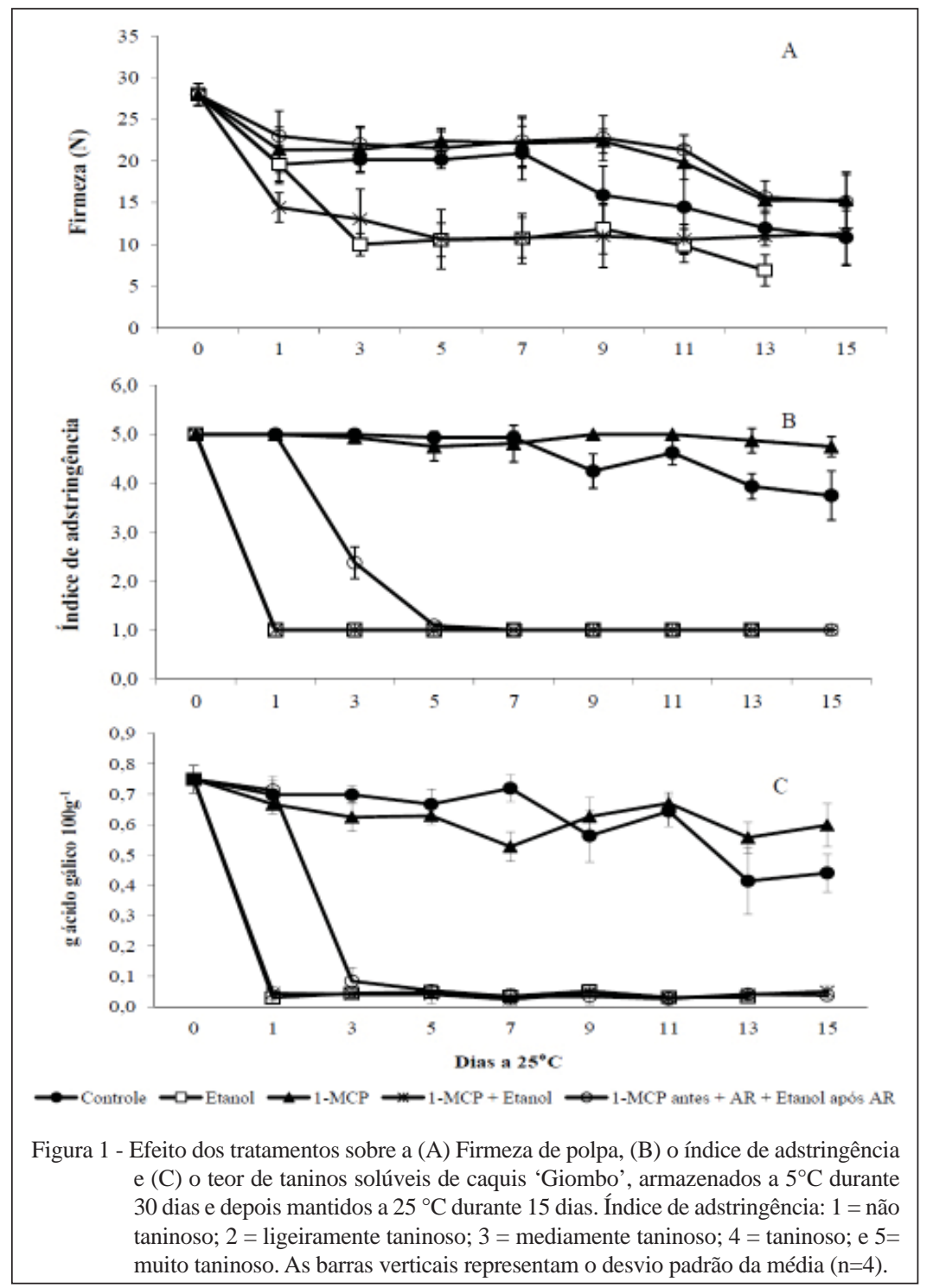

verificaram efeito semelhante do 1-MCP em caquis 'Rendaji' destanizados com etanol e armazenados a $20^{\circ} \mathrm{C}$. No presente trabalho, os frutos tratados com 1-MCP apresentaram manutenção da firmeza de polpa, inclusive aqueles que posteriormente foram submetidos aos vapores de etanol, apresentando, ao final de 15 dias de armazenamento, valores de firmeza superiores aos frutos do controle, o que pode ser considerado interessante para a manutenção da qualidade dos frutos.

Os frutos dos tratamentos que envolveram a aplicação de vapor de etanol apresentaram perda da adstringência no decorrer no período de armazenamento, avaliada por meio do índice de adstringência (Figura 1B). Essa queda na adstringência ocorreu bruscamente no tratamento em que os frutos foram tratados apenas com etanol ou quando o etanol foi aplicado imediatamente após a aplicação do 1-MCP. Para frutos desses tratamentos, o índice 1 (não taninoso) foi observado logo no primeiro dia após a retirada dos frutos do armazenamento refrigerado, mantendo-se assim durante todo o período de armazenamento em temperatura ambiente. Já nos frutos tratados com 1-MCP + AR + etanol não houve queda tão brusca no índice de adstringência, tendo atingido o índice 1 no quinto dia de armazenamento em temperatura ambiente.

Como esperado, os frutos tratados apenas com 1-MCP não apresentaram perda de adstringência durante o período de armazenamento em temperatura ambiente. Frutos tratados com 1-MCP apresentaram índices próximos a 5 (muito taninoso) até o último dia 
de análise. Esses dados corroboram aqueles obtidos de firmeza e comprovam a eficácia do 1-MCP em retardar o processo de amadurecimento e senescência dos frutos, sendo que, no caso dos caquis do grupo variável, ele retarda a perda natural de adstringência.

Os frutos não tratados (controle) tiveram leve queda no índice de adstringência a partir do nono dia de armazenamento, mantendo-se com um índice ao redor de 4 (taninoso) até o último dia de armazenamento. Essa diminuição no índice de adstringência no final do período de armazenamento pode estar relacionada com o amadurecimento e perda de firmeza de polpa dos frutos, considerando que, durante o amolecimento, ocorre aumento das pectinas solúveis, liberadas pela degradação das paredes celulares. Essas pectinas podem sofrer interações covalentes e não covalentes com as moléculas de taninos solúveis, formando polímeros de taninos, tornando-os insolúveis e, assim, removendo a adstringência dos frutos (EDAGI \& KLUGE, 2009). Tal ação das pectinas solúveis pode ser a explicação da diminuição da adstringência de frutos que não sofreram qualquer tratamento de destanização e estão em um estádio de maturação avançado (TAIRA et al., 1997).

De maneira geral, a tendência do conteúdo de taninos solúvies foi similar à tendência dos níveis de adstringêcia (Figura 1B e 1C). Os frutos tratados com etanol tiveram queda acentuada nos valores de taninos solúveis logo nos primeiros dias de avaliação (Figura 1C). Tal fato ocorreu, principalmente, nos frutos dos tratamentos em que apenas o etanol foi aplicado e quando esse composto foi aplicado logo após o 1-MCP, já que os resultados remetem a valores de taninos solúveis próximos a zero logo no primeiro dia após a retirada dos frutos da refrigeração. Os frutos do tratamento 1-MCP + AR + etanol também apresentaram queda nos teores de taninos solúveis no terceiro dia de exposição a $25^{\circ} \mathrm{C}$, demonstrando que o 1-MCP aplicado de forma antecipada não exerce influência no processo de destanização com etanol. Os frutos do controle e aqueles tratados somente com o 1-MCP apresentaram tendência de leve decréscimo no teor de taninos solúveis ao longo do armazenamento, mas os valores foram bem superiores aos encontrados para os demais tratamentos.

Ficou evidenciado no presente trabalho que o caqui 'Giombo' necessita de tratamento que promova a destanização dos frutos, pois os frutos não tratados mantiveram altos níveis de adstringência e teores de taninos solúveis durante 15 dias em temperatura de $25^{\circ} \mathrm{C}$. O 1-MCP aplicado isoladamente teve efeito semelhante, impedindo a perda da adstringência, embora tenha mantido altos níveis de firmeza de polpa. Esse composto, quando aplicado antes da refrigeração, em frutos que posteriormente foram tratados com etanol (1-MCP + AR + etanol), manteve mais alta a firmeza de polpa em relação aos frutos que foram submetidos ao etanol imediatamente à aplicação do 1-MCP e àqueles tratados apenas com etanol. Ainda em relação a esse tratamento, pôdese observar que, embora tenha atrasado em cinco dias o processo de destanização, ele pode ser útil para a manutenção de frutos mais firmes durante a comercialização e com baixo teor de taninos.

A destanização natutal de caquis ocorre devido ao processo de amolecimento da polpa, fatores estes relacionados à maturação e ação do etileno. Esse tipo de destanização ocorre pela polimerização dos taninos solúveis pelas pectinas solúveis libertadas das paredes celulares dutante o amolecimento dos frutos (NAKANO et al., 2002; EDAGI \& KLUGE, 2009). Com a aplicação do 1-MCP, houve a redução do amolecimento dos frutos e consequente redução o processo de destanização natural. Por esse motivo, houve a necessidade da remoção artificial da adstringência com uso de etanol. Nesse processo, o etanol penetra na polpa dos frutos induzindo a formação de acetaldeídos que polimerizam os taninos solúveis (SUGIURA \& TOMANA, 1983).

\section{CONCLUSÃO}

A aplicação do 1-MCP (1000nL L $\left.{ }^{-1}\right)$ antes da refrigeração a $5^{\circ} \mathrm{C}$, associado à destanização com etanol (3,5 $\mathrm{mL} \mathrm{kg}^{-1}$ fruto) após a refrigeração, promove a redução da perda de firmeza e da adstringência em caquis 'Giombo', possibilitando a comercialização dos frutos por até 11 dias.

\section{REFERÊNCIAS}

AGOSTINI-COSTA, T.S. et al. Avaliação de metodologias para a determinação de taninos no suco de caju. Boletim do CEPPA, v. 17, n. 2, p.167-178, 1999.

ANTONIOLLI, L.R. et al. Remoção da adstringência de frutos de caqui ‘Giombo' sob diferentes períodos de exposição ao vapor de etanol. Pesquisa Agropecuária Brasileira, v. 35, n. 10, p. 20832091, 2000. Disponível em: <http://dx.doi.org/10.1590/S0100204X2000001000021>. Acesso em: 17 out. 2011. doi: 10.1590/ S0100-204X2000001000021.

ANTONIOLLI, L.R. et al. Influência da embalagem de polietileno na remoção da adstringência e na qualidade de caquis (Diospyrus kaki L.). Revista Brasileira de Fruticultura, v.23, n.2, p.293297, 2001. Disponível em: <http://dx.doi.org/10.1590/S010029452001000200018>. Acesso em: 16 out. 2011. doi: 10.1590/ S0100-29452001000200018. 
ANTONIOLLI, R.C. et al. Remoção da adstringência de frutos de caquizeiro 'Giombo' sob diferentes temperaturas. Pesquisa Agropecuária Brasileira, v. 37, n. 5, p. 687-691, 2002. Disponível em: <http://dx.doi.org/10.1590/S0100204X2002000500014>. Acesso em: 17 out. 2011. doi: 10.1590/ S0100-204X2002000500014.

ARNAL, L.; DEL RÍO, M.A. Effect of cold storage and removal astringency on quality of persimmon fruit (Diospyros kaki L.) cV. 'Rojo Brillante'. Food Science and Technology International, v. 10, p. 179-185, 2004. Disponível em: <http://dx.doi. org/10.1177/1082013204044824>. Acesso em: 27 out. 2011. doi: $10.1177 / 1082013204044824$

BLANKENSHIP, S.M.; DOLE, J.M. 1-Methylcyclopropene: a review. Postharvest Biology and Technology, v. 28, p. 1-25, 2003. Disponível em: <http://dx.doi.org/10.1016/S09255214(02)00246-6>. Acesso em: 15 maio 2011. doi: 10.1016/ S0925-5214(02)00246-6.

BLUM, J. et al. Uso de cera na conservação pós-colheita de caqui cv 'Giombo'. Revista Brasileira de Fruticultura, v. 30, n. 3, p. 830-833, 2008. Disponível em: <http://dx.doi.org/10.1590/S010029452008000300046>. Acesso em: 3 jan. 2013. doi: 10.1590/ S0100-29452008000300046.

CAMARGO FILHO, W.P. et al. Mercado de caqui: Variedades, estacionalidade e preços. Informações Econômicas, v.33, n.10, p.81-87, 2003. Disponível em: <http://www.iea.sp.gov.br/out/ publicacoes/pdf/seto1-1003.pdf>. Acesso em: 27 dez. 2012.

CAMPO-DALL'ORTO, F.A. et al. Novo processo de avaliação da adstringência dos frutos no melhoramento do caquizeiro. Bragantia, v. 55, n. 2, p. 237-243, 1996. Disponível em: <http:// dx.doi.org/10.1590/S0006-87051996000200005>. Acesso em: 22 nov. 2010. doi: 10.1590/S0006-87051996000200005.

CARVALHO, C.R.L. et al. Análises químicas de alimentos. Campinas: ITAL, 1990. 121p. (Manual Técnico).

CRISOSTO, C.H. et al. Persimmons: recommendations for maintaining postharvest quality. Davis: UC Davis. Disponível em: $<$ http//:postharvest.ucdavis.edu/produce/storage.html $>$. Acesso em: 22 nov. 2011.

CHITARRA, M.I.F.; CHITARRA, A.B. Pós-colheita de frutas e hortaliças: fisiologia manuseio. 2.ed. Lavras: ESAL; FAEPE, 2005. 320p.

EDAGI, F.K.; KLUGE, R.A. Remoção de adstringência de caqui (Diospyros kaki L.): um enfoque bioquímico, fisiológico e tecnológico. Ciência Rural, v. 39, n. 2, p. 585594, 2009. Disponível em: <http://dx.doi.org/10.1590/S010384782009000200046>. Acesso em: 14 out. 2011. doi: 10.1590/ S0103-84782009000200046.

EDAGI, F.K. et al. Remoção da adstringência de caquis 'Giombo' com subdosagens de etanol. Ciência Rural, v. 39, n. 7, p. 20222028, 2009. Disponível em: <http://dx.doi.org/10.1590/S010384782009005000165>. Acesso em: 05 set. 2011. doi: 10.1590/ S0103-84782009005000165.

GIRARDI, C.L. et al. Conservação de caqui (Diospyros kaki L.), cv. 'Fuyu', pela aplicação de 1-metilciclopropeno. Revista Brasileira de Fruticultura, v. 25, n. 1, p. 54-56, 2003. Disponível em:
<http://dx.doi.org/10.1590/S0100-29452003000100016>. Acesso em: 30 out. 2011. doi: 10.1590/S0100-29452003000100016.

HARIMA, S. et al. Extending shelf-life of astringent persimmon (Diospyros kaki Thunb.) fruit by 1-MCP. Postharvest Biology and Technology, v.29, p.318-323, 2003. Disponível em: <http:// dx.doi.org/10.1016/S0925-5214(03)00058-9>. Acesso em: 17 out. 2011. doi: 10.1016/S0925-5214(03)00058-9.

LUO, Z. Effect of 1-methylcyclopropene on ripening of postharvest persimmon (Diospyros kaki L.) fruit. LWT-Food Science and Technology, v. 40, n. 2, p. 285-291, 2007. Disponível em: <http:// dx.doi.org/10.1016/j.lwt.2005.10.010>. Acesso em: 16 out. 2011. doi: 10.1016/j.lwt.2005.10.010.

MARTINS, F.P.; PEREIRA, F.M. Cultura do caquizeiro. Jaboticabal:FUNESP, 1989. 71p.

NAKANO, R. et al. Water stress induced ethylene in calyx triggers autocatalytic ethylene production and fruit softening in forcing-cultured 'Tonewase' persimmon. Postharvest Biology and Technology, v. 25, p. 293-300, 2002. Disponível em: <http:// dx.doi.org/10.1016/S0925-5214(02)>. Acesso em: 19 jan. 2012. doi: 10.1016/S0925-5214(02).

NAKANO, R. et al. Ethylene biosynthesis in detached young persimmon fruit is initiated in calyx and modulated by water loss from the fruit. Plant Physiology, v. 131, p. 276-286, 2003. Disponível em: <http://dx.doi.org/ 10.1104/pp.010462>. Acesso em: 19 jan. 2012. doi: 10.1104/pp.010462.

ORTIZ, G.I. et al. Efficacy of 1-methylcyclopropene in prolonging the shelf-life of 'Rendaiji' persimmon fruits previously subjected to astringency removal treatments. Journal of the Japanese Society for Horticultural Science, v. 74, n. 3, p.248-254, 2005. Disponível em: <http://dx.doi.org/10.2503/jjshs.74.248>. Acesso em: 03 out. 2011. doi: 10.2503/jjshs.74.248.

OSHIDA, M. et al. On the nature of coagulated tannins in astringency-type persimmon fruit after an artificial treatment of astringency removal. Postharvest Biology and Technology, v. 8, n. 4, p. 317-327, 1996. Disponível em: <http://dx.doi.org/ 10.1016/0925-5214(96)00016-6>. Acesso em: 22 set. 2011. doi: 10.1016/0925-5214(96)00016-6.

PEREIRA, W.S.P.; BELTRAN, A. Mecanismo de ação e uso do 1-MCP - bloqueador de etileno, visando prolongar a vida útil das frutas. In: ZAMBOLIM, L. (Ed.). Manejo integrado: fruteiras tropicais - doenças e pragas. Viçosa: Universidade Federal de Viçosa, 2002. V. 1, p. 31-44.

PERÉZ-MUNUERA, I. et al Influence of ripening stage at harvest on chilling injury symptoms of persimmon cv. 'Rojo Brillante' stored at different temperatures. Food Science and Technology International, v. 11, p.359-365, 2005. Disponível em: <http:// dx.doi.org/10.1177/1082013205057941>. Acesso em: 22 set. 2011. doi: $10.1177 / 1082013205057941$.

PIO, R. et al. A cultura do caquizeiro. Piracicaba: ESALQDivisão de Biblioteca e Documentação, 2003. 35p. (Série Produtor Rural, n²3). Disponível em: <http://www.esalq.usp.br/biblioteca/ PUBLICACAO/SP23/index>. Acesso em: 28 dez. 2012.

PROGRAMA BRASILEIRO PARA A MODERNIZAÇÃO DA HORTICULTURA. Normas de classificação do caqui. São Paulo: CEAGESP, Centro de Qualidade em Horticultura, 2000. (CQH. Documentos, 22). 
SALVADOR, A. et al. Influence of ripening stage at harvest on chilling injury symptoms of perssimmon cv. 'Rojo Brilhante' stored at different temperatures. Food Science and Technology International, v. 11, p. 359-365, 2005. Disponível em: <http:// dx.doi.org/10.1177/1082013205057941>. Acesso em: 10 mar. 2011. doi: 10.1177/1082013205057941.

SALVADOR, A. et al. Physiological and structural changes during ripening and deastringency treatment of persimmon fruit cv. 'Rojo Brillante'. Postharvest Biology and Technology, v. 46, n. 1 p. 181-188, 2007. Disponível em: <http://dx.doi.org/10.1016/j. postharvbio.2007.05.003>. Acesso em: 22 set. 2011 . doi: 10.1016/j.postharvbio.2007.05.003.

SISLER, E.C.; SEREK, M. Inhibitors of ethylene responses in plants at the receptors level: recent developments. Physiologia Plantarum, v. 100, p. 577-582, 1997. Disponível em: <http:// dx.doi.org/ 10.1034/j.1399-3054.1997.1000320.x>. Acesso em: 03 out. 2011. doi: 10.1034/j.1399-3054.1997.1000320.x.

SUGIURA, A.; TOMANA, T. Relationships of ethanol production by seeds of different types of Japanese persimmons and their tannin content. HortScience, v. 18, n. 3, p. 319-321, 1983.

TAIRA, S. et al. formation between pectin and tannins. Postharvest Biology and Technology, v. 12, p. 265-271, 1997. Disponível em: <http://dx.doi.org/ 10.1016/S0925-5214(97)00064-1>. Acesso em: 22 set.2011. doi: 10.1016/S0925-5214(97)00064-1..

WATKINS, C.B. The use of 1-methylcyclopropene (1-MCP) on fruits and vegetables. Biotechnology Advances, v. 24, p. 389-409, 2006. Disponível em: <http://dx.doi.org/10.1016/j. biotechadv.2006.01.005>. Acesso em: 20 jun. 2012. doi: 10.1016/j.biotechadv.2006.01.005. 